\title{
Heart rate variability is related to self-reported physical activity in a healthy adolescent population
}

\author{
Eva Henje Blom • Erik M. G. Olsson • \\ Eva Serlachius $\cdot$ Mats Ericson $\cdot$ Martin Ingvar
}

Accepted: 11 May 2009 / Published online: 29 May 2009

(C) The Author(s) 2009. This article is published with open access at Springerlink.com

\begin{abstract}
This study investigated whether there is a relationship between heart rate variability (HRV) versus lifestyle and risk factors for cardiovascular disease in a population of healthy adolescents. HRV is as an index of tonic autonomic activity and in adults HRV is related to lifestyle and risk factors for cardiovascular disease, but it is not known if this is the case in adolescents. HRV was registered for $4 \mathrm{~min}$ in sitting position in 99 healthy adolescents (age range 15 years 11 months -17 years 7 months) and repeated after 6 months. On both occasions there were significant correlations $(P<0.05)$ between physical activity and HRV, with respective
\end{abstract}

E. Henje Blom $(\bowtie)$

Department of Clinical Neuroscience,

Osher Center for Integrative Medicine,

Karolinska Institutet, 17176 Stockholm, Sweden

e-mail: eva.henjeblom@ki.se

E. M. G. Olsson

Department of Psychology, Uppsala University,

Box 256, 75105 Uppsala, Sweden

e-mail: erik.olsson@psyk.uu.se

E. Serlachius

Department of Woman and Child Health,

Osher Center for Integrative Medicine,

Karolinska Institutet, 17176 Stockholm, Sweden

e-mail: eva.serlachius@ki.se

M. Ericson

Swedish National Defence College,

Box 278 05, 11593 Stockholm, Sweden

e-mail: mats.ericson@fhs.se

M. Ingvar

Department of Clinical Neuroscience,

Osher Center for Integrative Medicine,

Karolinska University Hospital, 17176 Stockholm, Sweden

e-mail: martin.ingvar@ki.se $r$ values: high frequency (HF) 0.26, 0.30; low frequency power (LF) $0.35,0.29$ and the standard deviation of interbeat intervals $(\mathrm{SDNN}) 0.28,0.37$. There was no significant interaction between first and second measurements. In contrast, there were no correlations to sleeping patterns, eating habits and smoking. Risk factors for cardiovascular disease [body mass index $\left(\mathrm{BMI}=\right.$ weight $(\mathrm{kg}) /$ length in $\left.\mathrm{m}^{2}\right)$, systolic blood pressure and p-glucose] did not show any repeatable significant correlations to HRV. Multiple regression models showed that physical activity was a predictor for HF, LF and SDNN in both measurements. In conclusion HF, LF and SDNN were reproducible after 6 months and were related to physical activity on both occasions.

Keywords Lifestyle $\cdot$ Physical activity

\section{Introduction}

Heart rate variability (HRV) is related to lifestyle in adults. Regular physical exercise in adults has beneficial effect on autonomic control of the heart, with decreased resting heart rate often accompanied with increase in HRV (Hottenrott et al. 2006; Tuomainen et al. 2005). Disturbed sleeping patterns or lack of sleep effect HRV. Shift workers and patients with sleep apnoea have deranged HRV (Furlan et al. 2000; Gula et al. 2003). Smoking impairs the sympatho-vagal balance and decreases the HRV in healthy adults (Alyan et al. 2008; Karakaya et al. 2007) and in heavy smokers vagal modulation of the heart is blunted (Barutcu et al. 2005).

In adolescent HRV decreases with augmented BMI (Rabbia et al. 2003) as it does with blood glucose levels (Singh et al. 2000) and risk factor influence on autonomic heart rate control is present before manifest cardiovascular disease (Jensen-Urstad et al. 1998). The relationship between HRV 
and lifestyle is not well studied in children and adolescents and it is not known at what age the relationship is established.

There is a modification of HRV with age, which reflects the evolution of the autonomic nervous system (Silvetti et al. 2001). LF, HF and total power increase from 0-6 years, followed by a decrease to adulthood (Finley and Nugent 1995). Early life individual differences in HRV can be explained by hereditary factors (Singh et al. 2002), diabetic neuropathy (Colhoun et al. 2001) or an underdeveloped ANS in prematurely born children (Longin et al. 2006).

Decreased HRV is associated with risk for cardiac events in adults (Tsuji et al. 1996) and is a predictor of imminent hypertension (Schroeder et al. 2003; Singh et al. 1998). A decreased HRV is related to an increased risk of death and HRV could have a predictive value for life expectancy and health (Tsuji et al. 1996).

Our hypothesis is that HRV changes due to lifestyle factors precedes or parallels the development of cardiovascular disorders, i.e. it should present also in healthy adolescents, where long-term effects of poor lifestyle has not yet generated manifest cardiovascular disease. To this end we investigated whether there is an impact of lifestyle (physical activity, eating habits, sleeping pattern and smoking) on autonomic heart rate control in healthy adolescents, i.e. at an age when lifestyle-associated cardiovascular disorders are not yet frequent. The impacts of cardiovascular risk factors (systolic blood pressure, p-glucose and BMI) on HRV were also studied.

\section{Methods}

High school students (66 girls and 33 boys) with mean age 16.5 years at the first measurement (age range 15 years 11 months -17 years 7 months) constituted the original sample. The subjects were recruited from high schools: in a small rural town, in the Stockholm city, in a northern affluent suburb and in a less affluent southern suburb with a large immigrant population. The first author met the students and gave oral and written information about the study and an informed consent form was signed by the student and at least one parent. The measurements had the same order in all subjects. The measurements were repeated after 6 months to evaluate the stability of the intra-individual HRV. When both measurements were completed, the students were offered two cinema tickets each. About $80 \%$ of the students informed participated and no one was denied participation. The participation ratio was similar for all schools. The main reasons to decline participation were fear of blood sampling and not wanting to miss school hours. Exclusion criteria were diabetes, thyroid dysfunction and more than $5 \%$ missing or distorted data in any registered HRV segment. The study was approved by the Regional Ethics Committee at Karolinska Institutet.
The measurements were carried out at the school nurses offices by four nurses and one physician. The subjects were sitting upright, in silence and no body movements were allowed during the procedure. None of the subjects had clinical signs or symptoms of infectious disease. Use of tobacco or intake of tea, coffee, caffeine containing soft drinks or beta stimulant asthma medication was not allowed $1 \mathrm{~h}$ prior to the measurements.

The HRV registration was preceded by $15 \mathrm{~min}$ of rest. HRV was measured during 2 min $\times 2$, in between which blood pressure was checked. This was a modified version of a 12-min protocol (von Scheele et al. 2005).

SDNN was used as a time domain measure and HF and LF as frequency domain measures. In spectral analyses variability distributes as a function of frequency (Camm 1996). HF (0.15-0.4 Hz) is related to vagal activity and includes the respiratory sinus arrhythmia when the breathing rate is normal. LF $(0.04-0.15 \mathrm{~Hz})$ is a quantitative marker for sympathetic modulations, but in some studies it is viewed as reflecting both sympathetic and vagal activity (Berntson et al. 1997). The equipment was a I-330-C-2 Physiological Monitoring System (J\&J Engineering; Poulsbo, WA), and c-Stress customized software (PBM Systems, Stockholm, Sweden). The electrocardiogram (ECG) was recorded from electrodes placed on the left and right wrist with a sampling rate of $1,024 \mathrm{~Hz}$. Inter-beat intervals were calculated online using an $\mathrm{R}$-wave peak detection algorithm and stored on a PC for off-line processing. Fourier analysis was performed on 2-min segments of detrended data passed through a Hamming window. The HRV mean values were logarithmically transformed. Inter-beat intervals were scanned manually for ectopic beats and artefacts, which were replaced with cubic spline interpolation.

Lifestyle was self-reported in a form with five-point scales. Sleeping patterns were described by frequency of going to bed later than midnight ("never", "seldom", "1 time/week", "2 times/week", ">2 times per week"), food habits by the frequency of missing breakfast and/or lunch ("never", "seldom", "1-2 days/week", “3-4 days/week" or "every day"), physical exercise by the frequency of exercising with hard breathing and sweating ("never", "seldom", "once a week", "twice a week" and "more than twice a week"). Smoking was defined as daily smoking or not. Socio-demographic data was represented by school, number of parents in the household, parent unemployment and parent ethnicity.

Capillary p-glucose and b-haemoglobin were analysed with a portable Heamocue Glucose and Haemoglobin System (Banauch et al. 1975; Vanzetti 1966). Weight and length were measured and BMI calculated. The same equipment was used throughout the whole study for measuring weight and blood pressure. 


\section{Statistics}

Results are given as means and standard deviations (SD). Non-normally distributed values were logarithmically transformed before analyses. Two-tailed group analyses were done with $t$ test, but when normal distributions were not present it was performed with Mann-Whitney's $U$ test. Bi- and multi-variate relations among the variables were assessed by Pearson's product-moment correlation or, in case of variables of an ordinal nature, by Spearman's rank correlation. Partial correlations were used to remove the effect of confounding variables. Stability of repeated measures was calculated with paired $t$ test or, in case of ordinal variables, the Wilcoxon matched pairs test was used. Possible differences in correlation structure between the two test periods were checked with structural equation modelling. Multivariate relations were further explored by principal component analysis in order to get a stable foundation for the construction of regression models. Such regression models were then further refined by using stepwise models or 'best subset' models with Mallow's Cp as the criterion for best fit. Probability levels of 0.05 or less were considered significant. All analyses were done in Statistica 8.0 (http://www.statsoft.com).

\section{Results}

\section{Study population}

One subject with diabetes and one with thyroid dysfunction were excluded. In the first measurements, 20 subjects were excluded because of poor quality of registered HRV data ( $>5 \%$ of missing or distorted beats). The final sample included 77 subjects for the first occasion. In the repeated measurements, four subjects failed to appear (change of school or sick leave) and one handed in incomplete data. One exclusion was done due to poor quality of HRV registration. 71 subjects had full data from both measurements, and constituted the basis for all correlations that are reported. In the original sample $68.4 \%$ were girls. $64.4 \%$ lived with both of their parents, $75.0 \%$ had both parents employed and $67.1 \%$ had both parents born in Sweden. The excluded subjects did not differ significantly from the original sample, but the exclusions were unevenly distributed among the schools $(P<0.1)$ (Table 1$)$.

\section{Repeated measures}

Significant correlations $(P<0.05)$ were found between the first and repeated measurement, with $r$ values for $\mathrm{HF}(0.54)$, LF (0.62) and SDNN (0.64). The correlations between measurements increased slightly when controlled for heart rate,
Table 1 Comparison between included and excluded subjects on background variables in the original sample

\begin{tabular}{llccc}
\hline & Included & Excluded & $\chi^{2}$ & $P$ \\
\hline$n$ & 71 & 28 & & \\
Sex & & & 0.02 & 0.87 \\
Males & 24 & 9 & & \\
Females & 47 & 19 & & \\
School & & & 10.0 & 0.02 \\
1. Rural & 13 & 10 & & \\
2. Northern affluent suburb & 18 & 4 & & \\
3. City centre & 18 & 1 & & \\
4. Southern suburb & 22 & 13 & & \\
Family situation & & & 0.78 & 0.38 \\
Live with two parents & 52 & 18 & & \\
Live with single parent & 19 & 10 & & \\
Parents occupational status & & & 0.63 & 0.43 \\
Both parents employed & 53 & 23 & & \\
At least one parent unemployed & 18 & 5 & & \\
Parents ethnical background & & & & \\
Both parents of foreign origin & 10 & 11 & & \\
At least one parent Swedish & 61 & 17 & & \\
\hline
\end{tabular}

with $r$ values for HF (0.66), LF (0.65), SDNN (0.66). Structural equation modelling did not identify any differences in correlation structure between the two test periods. The correlations between the first and repeated measurement were also significant for BMI (0.94), systolic blood pressure (0.69) and p-glucose (0.32). No significant differences were found in socio-demographic and lifestyle parameters between the two measurements (Table 2).

Gender

In the final sample $64.4 \%$ were girls. Boys had a higher frequency of physical activity and girls a higher frequency of skipping meals. No gender differences were found in sleeping patterns. Only eight subjects were daily smokers of which six were girls. BMI and p-glucose showed no gender differences, whereas systolic blood pressure was higher in boys, as expected from gender-specific reference values. Girls had a significantly higher heart rate compared to boys but no significant differences were found in the HF, LF or SDNN. Further analyses were therefore presented as one group (Table 3 ).

Relationship between HRV versus lifestyle and risk factors for cardiovascular disease

Significant correlations $(P<0.05)$ were found between self-reported physical activity and HF, LF, SDNN and heart rate on both the first and second measurement (Table 4). 
Table 2 Comparison between the first and the repeated measurement after 6 months with paired $t$ test $(N=71)$

\begin{tabular}{llrr}
\hline & $\begin{array}{l}\text { First measurement } \\
\text { mean (SD) }\end{array}$ & $\begin{array}{l}\text { Second measurement } \\
\text { mean (SD) }\end{array}$ & $t$ value \\
\hline Log HF $^{\mathrm{b}}$ & $5.88(0.93)$ & $5.90(1.04)$ & -0.13 \\
$\mathrm{Log} \mathrm{LF}^{\mathrm{c}}$ & $6.03(0.90)$ & $6.20(1.04)$ & -1.72 \\
$\mathrm{SDNN}^{\mathrm{c}}$ & $4.11(0.35)$ & $4.18(0.38)$ & -1.86 \\
Heart rate & $74.5(9.63)$ & $71.43(10.65)$ & 0.09 \\
p-glucose & $5.6(0.76)$ & $5.4(0.71)$ & 0.07 \\
BMI $^{\mathrm{d}}$ & $22.3(3.39)$ & $22.7(3.43)$ & 0.01 \\
Systolic blood pressure & $115(10.4)$ & $111(9.77)$ & 0.01 \\
Single parent status & $28.8 \%$ & $27.8 \%$ & 0.02 \\
Both parents of foreign origin & $15.2 \%$ & $15.2 \%$ & 3.99 \\
At least one parent unemployed & $26.0 \%$ & $20.8 \%$ & 0.001 \\
Physical activity & $3.93(1.17)$ & $3.86(1.18)$ & 0.31 \\
Irregular eating habits & $2.14(1.24)$ & $2.02(1.20)$ & 0.63 \\
Late sleeping pattern & $2.64(1.52)$ & $2.54(1.44)$ & 0.1 .42 \\
\hline
\end{tabular}

${ }^{a}$ Standard deviation, ${ }^{b}$ Logarithmically transformed high frequency power of $\mathrm{HRV},{ }^{\mathrm{c}}$ Logarithmically transformed low frequency power of HRV,

${ }^{\mathrm{d}}$ Logarithmically transformed standard deviation of inter-beat intervals, ${ }^{\mathrm{e}}$ Body mass index

Table 3 Sex differences in the HRV measures, heart rate, clinical characteristics and blood chemistry

\begin{tabular}{|c|c|c|c|c|}
\hline & Mean $(\mathrm{SD})^{\mathrm{a}} / n^{\mathrm{b}}(\%)$ girls & Mean $(\mathrm{SD}) / n(\%)$ boys & $t$ value $/ \chi^{2}$ & $P$ \\
\hline$n$ & 47 & 24 & & \\
\hline Living with single parent & $12(25.5 \%)$ & $7(29.2 \%)$ & 0.11 & 0.74 \\
\hline At least one parent unemployed & $12(25.5 \%)$ & $6(25.0 \%)$ & 0.00 & 0.96 \\
\hline Both parents of foreign origin & $8(17.0 \%)$ & $2(8.3 \%)$ & 0.99 & 0.32 \\
\hline Number of daily smokers & $6(12.8 \%)$ & $1(4.212 .5 \%)$ & 1.33 & 0.25 \\
\hline Physical activity (frequency index) & $3.5(1.14)$ & $4.7(0.82)$ & -4.44 & $<0.001$ \\
\hline Irregular eating habits (frequency index) & $2.4(1.25)$ & $1.5(0.98)$ & 3.03 & 0.003 \\
\hline Late sleeping habits (frequency index) & $2.7(1.49)$ & $2.7(1.65)$ & -0.07 & 0.94 \\
\hline $\mathrm{P}-$ glucose $(\mathrm{mmol} / \mathrm{L})$ & $5.52(0.74)$ & $5.90(0.79)$ & -1.99 & 0.05 \\
\hline Haemoglobin $(\mathrm{g} / \mathrm{L})$ & $129.7(12.25)$ & $145.5(10.25)$ & -5.32 & $<0.001$ \\
\hline Body Mass Index $\left(\mathrm{kg} / \mathrm{m}^{2}\right)$ & $22.4(3.73)$ & $22.3(2.75)$ & 0.03 & 0.98 \\
\hline Systolic blood pressure $(\mathrm{mmHg})$ & $112.1(9.53)$ & $121.2(9.75)$ & -3.79 & $<0.001$ \\
\hline Heart rate (beats per min) & $76.74(9.51)$ & $70.30(8.75)$ & 2.77 & 0.007 \\
\hline $\log H F^{c}$ & $5.94(0.81)$ & $5.80(1.17)$ & 0.60 & 0.55 \\
\hline $\log L^{d}$ & $5.99(0.88)$ & $6.14(0.97)$ & -0.64 & 0.52 \\
\hline $\log \operatorname{SDNN}^{\mathrm{e}}$ & $4.09(0.32)$ & $4.17(0.40)$ & -0.90 & 0.37 \\
\hline
\end{tabular}

${ }^{\mathrm{a}}$ Standard deviation, ${ }^{\mathrm{b}}$ Number, ${ }^{\mathrm{c}}$ Logarithmically transformed high frequency power of HRV, ${ }^{\mathrm{d}}$ Logarithmically transformed low frequency power of HRV, ${ }^{\mathrm{e}}$ Logarithmically transformed standard deviation of inter-beat intervals

The correlations between physical activity and LF remained significant when controlled for heart rate, with a correlation coefficient of 0.27 in the first and 0.23 in the second measurement. This was not the case for HF and SDNN. Late sleeping patterns, eating habits and smoking showed no significant correlations to HRV in any of the measurements. BMI, p-glucose and systolic blood pressure did not show any significant correlations to HF, LF, SDDN or heart rate on any of the measurements except p-glucose, which correlated to SDNN in the first measurement (0.24).

Multiple regression models showed that physical activity (but not sleeping pattern, eating habits or smoking) predicted HF, LF and SDNN on both measurements. Physical activity predicted LF (but not HF and SDNN) also when heart rate was controlled for in both measurements. Of the cardiovascular risk factors only p-glucose showed a weak but significant prediction power for LF in the second 
Table 4 Correlation coefficients between lifestyle parameters and heart rate variability

\begin{tabular}{|c|c|c|c|c|c|c|c|c|}
\hline & \multicolumn{4}{|c|}{ First measurement } & \multicolumn{4}{|c|}{ Second measurement } \\
\hline & Heart rate & $\log \mathrm{HF}^{\mathrm{a}}$ & $\log \mathrm{LF}^{\mathrm{b}}$ & $\log \mathrm{SDNN}^{\mathrm{c}}$ & Heart rate & $\log \mathrm{HF}$ & $\log \mathrm{LF}$ & Log SDNN \\
\hline \multicolumn{9}{|c|}{ Physical activity } \\
\hline $\begin{array}{l}r \\
(\text { partial } r)\end{array}$ & $\begin{array}{l}-0.37 * \\
(-0.35)^{*}\end{array}$ & $\begin{array}{l}0.26 * \\
(0.23)\end{array}$ & $\begin{array}{l}0.35^{*} \\
(0.36)^{*}\end{array}$ & $\begin{array}{l}0.28 * \\
(0.28)^{*}\end{array}$ & $\begin{array}{l}-0.42 * \\
(-0.44)^{*}\end{array}$ & $\begin{array}{l}0.30 * \\
(0.32)^{*}\end{array}$ & $\begin{array}{l}0.29 * \\
(0.29)^{*}\end{array}$ & $\begin{array}{l}0.37 * \\
(0.37)^{*}\end{array}$ \\
\hline \multicolumn{9}{|c|}{ Irregular eating habits } \\
\hline $\begin{array}{l}r \\
(\operatorname{partial} r)\end{array}$ & $\begin{array}{l}0.14 \\
(0.11)\end{array}$ & $\begin{array}{l}-0.06 \\
(-0.03)\end{array}$ & $\begin{array}{l}-0.16 \\
(-0.07)\end{array}$ & $\begin{array}{l}-0.18 \\
(-0.11)\end{array}$ & $\begin{array}{l}0.17 \\
(0.19)\end{array}$ & $\begin{array}{l}-0.05 \\
(-0.11)\end{array}$ & $\begin{array}{l}-0.16 \\
(-0.15)\end{array}$ & $\begin{array}{l}-0.09 \\
(-0.08)\end{array}$ \\
\hline \multicolumn{9}{|c|}{ Late sleeping pattern } \\
\hline $\begin{array}{l}r \\
(\operatorname{partial} r)\end{array}$ & $\begin{array}{l}-0.03 \\
(0.01)\end{array}$ & $\begin{array}{l}-0.00 \\
(-0.01)\end{array}$ & $\begin{array}{l}-0.08 \\
(-0.03)\end{array}$ & $\begin{array}{l}-0.07 \\
(-0.05)\end{array}$ & $\begin{array}{l}-0.02 \\
(-0.02)\end{array}$ & $\begin{array}{l}-0.00 \\
(-0.03)\end{array}$ & $\begin{array}{l}-0.19 \\
(-0.20)\end{array}$ & $\begin{array}{l}-0.05 \\
(-0.05)\end{array}$ \\
\hline
\end{tabular}

Correlations significant at $P<0.05$ are marked with* $(N=71)$, partial correlations controlling for BMI, p-glucose, systolic blood pressure are in parenthesis

${ }^{a}$ Logarthmically transformed high frequency power of HRV, ${ }^{b}$ Logarithmically transformed low frequency power of HRV, ${ }^{\mathrm{c}}$ Logarithmically transformed standard deviation of inter-beat intervals

Table 5 Regression models showing the contribution of physical activity to HRV parameters and heart rate in the first and second measurement

\begin{tabular}{llllll}
\hline & \multicolumn{2}{l}{ First measurement } & & \multicolumn{2}{l}{ Second measurement } \\
\cline { 2 - 3 } \cline { 5 - 6 } & Multiple $R^{2}$ & Adjusted $R^{2}$ & & Multiple $R^{2}$ & Adjusted $R^{2}$ \\
\hline Log HF & 0.06 & 0.05 & 0.13 & 0.11 \\
Log LF & 0.11 & 0.09 & $0.17^{*}$ & $0.13^{*}$ \\
SDNN & 0.07 & 0.06 & 0.14 & 0.12 \\
Heart rate & 0.13 & 0.12 & 0.21 & 0.18 \\
\hline
\end{tabular}

These are 'best subset' models where physical activity was the sole significant predicting variable except in one case

* When only physical activity and not p-glucose was allowed in the general regression model the contribution to LF was estimated by multiple $R^{2} 0.08$ and adjusted $R^{2} 0.07$

measurement, but BMI and systolic blood pressure did not predict HRV (Table 5).

\section{Discussion}

The main finding of the present study was that self-reported physical activity but not eating habits, sleeping patterns or smoking predicted HF, LF and SDNN and heart rate in a healthy study population of adolescents. Of the cardiovascular risk factors only p-glucose showed a weak but significant prediction power for LF in the second measurement, but BMI and systolic blood pressure did not predict HRV.

No main effects were noted for gender except that heart rate was significantly lower in boys. SDNN showed no gender difference in the present study, but data are being reported as higher in adolescent boys compared to girls (Silvetti et al. 2001). However, the present data was in line with the Silvetti study in that boys had a lower heart rate and that vagus-associated parameters of HRV showed no gender differences.

In adults regular aerobic exercise results in reduction in heart rate, reflecting an increase in autonomic efferent activity with enhanced vagal influence on the cardiac rhythm (Hottenrott et al. 2006). This is in line with the present findings of adolescents. The effect of physical exercise on different HRV parameters is less clear-cut in previous studies. Low to moderate intensity exercise is associated with favourable changes in HRV in middle aged men (Tuomainen et al. 2005), but limited influence of physical training on HRV has also been reported (Buchheit and Gindre 2006). High intensity intermittent training in children during 7 weeks does not affect HRV (Gamelin et al. 2009). Physical activity in the present study is self-reported as a lifestyle parameter and probably reflects a longer duration of regular training than 7 weeks, which may explain the impact on HRV. Sleeping patterns are not related to HRV, which is in contrast to what has been reported in adult samples (Furlan et al. 2000). This may reflect that our sleep measure was less directed towards sleep deprivation and rather measured a shift in diurnal rhythm. The fact that smoking did not correlate to HRV may be a lack of sensitivity, as the subjects were few and had not smoked for extended periods, combined with the low reliability in self-reported tobacco use in this age group (Hennrikus et al. 2005). The lack of correlations between BMI and systolic blood pressure versus HRV are also probably due to lack of sensitivity, as few subjects suffered from obesity or hypertension in the sample. Multiple regression models in the second measurements showed a weak predictive power of p-glucose on LF. Our data support (Faulkner et al. 2003) in that HRV data allows for the early identification of subclinical cardiac autonomic changes in youth. 
The inferential power of the study is limited by that the sample encompassed only of 99 subjects, that we had some loss of data and the group did not represent a fully randomised population sample. However, the repeated measures design demonstrated that the reported regressions were robust within the sample.

The present findings support that even a short registration without any standardised interventions can capture HRV differences of possible predictive and clinical value. Fiveminute Holter recordings in a non-laboratory setting has been shown to be stable over 2 months and generate individually characteristic HRV data (Sinnreich et al. 1998). Our data show stable results with 4-min registrations over a period of 6 months. The registering of HRV only during 4 min (and not $24 \mathrm{~h}$ ) has obvious advantages for screening purposes. The HRV measurement device is portable and easily managed.

In conclusion, we have reported that HRV is related to self-reported physical activity in adolescents and thereby life style factors influence HRV at an age preceding the development of manifest lifestyle-related cardiovascular disorders. Within the age range of 15 years and 11 months to 17 years and 7 months, physical activity, but not sleeping pattern, eating habits or smoking was a predictor for HF, LF and SDNN. Of the cardiovascular risk factors, only p-glucose showed a weak predictive power for LF on one occasion. Whether the impact of physical exercise on HRV in adolescents is associated with a prognostic benefit regarding overall mortality, needs to be studied further. It would be of interest to target the impact of increased physical activity in young individuals with high exposure to known risk factors for cardiovascular disease using both HRV and future morbidity as endpoints. The present findings support that an ambulatory short registration of HRV can have possible predictive and clinical value.

Acknowledgments Thanks to all the students, teachers and school nurses, who have contributed to this study Financial support was obtained from Osher Center for Integrative Medicine, Karolinska Institutet, Sweden, Public Health Grants from the Stockholm County Council, The Swedish Society of Medicine, The National Board of Health and Welfare and The Söderström-Königska Foundation. Statistical support has been obtained by associate professor G. Granath in Uppsala.

Conflicts of interest statement None of the authors has conflict of interest.

Open Access This article is distributed under the terms of the Creative Commons Attribution Noncommercial License which permits any noncommercial use, distribution, and reproduction in any medium, provided the original author(s) and source are credited.

\section{References}

Alyan O, Kacmaz F, Ozdemir O, Maden O, Topaloglu S, Ozbakir C, Metin F, Karadede A, Ilkay E (2008) Effects of cigarette smoking on heart rate variability and plasma N-terminal pro-B-type natriuretic peptide in healthy subjects: is there the relationship between both markers? Ann Noninvasive Electrocardiol 13:137144. doi:10.1111/j.1542-474X.2008.00213.x

Banauch D, Brummer W, Ebeling W, Metz H, Rindfrey H, Lang H, Leybold K, Rick W, Staudinger HJ (1975) A glucose dehydrogenase for the determination of glucose concentrations in body fluids Z Klin Chem Klin Biochem 13:101-107 (author's transl)

Barutcu I, Esen AM, Kaya D, Turkmen M, Karakaya O, Melek M, Esen OB, Basaran Y (2005) Cigarette smoking and heart rate variability: dynamic influence of parasympathetic and sympathetic maneuvers. Ann Noninvasive Electrocardiol 10:324-329. doi:10.1111/j.1542-474X.2005.00636.x

Berntson GG, Bigger JT Jr, Eckberg DL, Grossman P, Kaufmann PG, Malik M, Nagaraja HN, Porges SW, Saul JP, Stone PH, van der Molen MW (1997) Heart rate variability: origins, methods, and interpretive caveats. Psychophysiology 34:623-648. doi:10.1111/ j.1469-8986.1997.tb02140.x

Buchheit M, Gindre C (2006) Cardiac parasympathetic regulation: respective associations with cardiorespiratory fitness and training load. Am J Physiol Heart Circ Physiol 291:H451-H458. doi:10.1152/ajpheart.00008.2006

Camm AJ (1996) Heart rate variability. Standards of measurement, physiological interpretation, and clinical use. Task Force of the European Society of Cardiology and the North American Society of Pacing and Electrophysiology. Eur Heart J 17:354-381

Colhoun HM, Francis DP, Rubens MB, Underwood SR, Fuller JH (2001) The association of heart-rate variability with cardiovascular risk factors and coronary artery calcification: a study in type 1 diabetic patients and the general population. Diabetes Care 24:1108-1114. doi:10.2337/diacare.24.6.1108

Faulkner MS, Hathaway D, Tolley B (2003) Cardiovascular autonomic function in healthy adolescents. Heart Lung 32:10-22. doi:10. 1067/mhl.2003.6

Finley JP, Nugent ST (1995) Heart rate variability in infants, children and young adults. J Auton Nerv Syst 51:103-108. doi:10.1016/ 0165-1838(94)00117-3

Furlan R, Barbic F, Piazza S, Tinelli M, Seghizzi P, Malliani A (2000) Modifications of cardiac autonomic profile associated with a shift schedule of work. Circulation 102:1912-1916

Gamelin FX, Baquet G, Berthoin S, Thevenet D, Nourry C, Nottin S, Bosquet L (2009) Effect of high intensity intermittent training on heart rate variability in prepubescent children. Eur J Appl Physiol 105:731-738. doi:10.1007/s00421-008-0955-8

Gula LJ, Krahn AD, Skanes A, Ferguson KA, George C, Yee R, Klein GJ (2003) Heart rate variability in obstructive sleep apnea: a prospective study and frequency domain analysis. Ann Noninvasive Electrocardiol 8:144-149. doi:10.1046/j.1542-474X.2003. 08209.x

Hennrikus D, Rindal DB, Boyle RG, Stafne E, Lazovich D, Lando H (2005) How well does the health history form identify adolescent smokers? J Am Dent Assoc 136:1113-1120

Hottenrott K, Hoos O, Esperer HD (2006) Heart rate variability and physical exercise. Current status. Herz 31:544-552. doi:10.1007/ s00059-006-2855-1

Jensen-Urstad M, Jensen-Urstad K, Ericson M, Johansson J (1998) Heart rate variability is related to leucocyte count in men and to blood lipoproteins in women in a healthy population of 35-yearold subjects. J Intern Med 243:33-40. doi:10.1111/j.1365-2796. 1998.00312.x

Karakaya O, Barutcu I, Kaya D, Esen AM, Saglam M, Melek M, Onrat E, Turkmen M, Esen OB, Kaymaz C (2007) Acute effect of cigarette smoking on heart rate variability. Angiology 58:620-624. doi: $10.1177 / 0003319706294555$

Longin E, Gerstner T, Schaible T, Lenz T, Konig S (2006) Maturation of the autonomic nervous system: differences in heart rate 
variability in premature vs term infants. J Perinat Med 34:303308. doi:10.1515/JPM.2006.058

Rabbia F, Silke B, Conterno A, Grosso T, De Vito B, Rabbone I, Chiandussi L, Veglio F (2003) Assessment of cardiac autonomic modulation during adolescent obesity. Obes Res 11:541-548. doi:10.1038/oby.2003.76

Schroeder EB, Liao D, Chambless LE, Prineas RJ, Evans GW, Heiss G (2003) Hypertension, blood pressure, and heart rate variability: the Atherosclerosis Risk in Communities (ARIC) study. Hypertension 42:1106-1111. doi:10.1161/01.HYP.0000100444.71069. 73

Silvetti MS, Drago F, Ragonese P (2001) Heart rate variability in healthy children and adolescents is partially related to age and gender. Int J Cardiol 81:169-174. doi:10.1016/S0167-5273(01) 00537-X

Singh JP, Larson MG, Tsuji H, Evans JC, O’Donnell CJ, Levy D (1998) Reduced heart rate variability and new-onset hypertension: insights into pathogenesis of hypertension: the Framingham Heart Study. Hypertension 32:293-297

Singh JP, Larson MG, O’ Donnell CJ, Wilson PF, Tsuji H, Lloyd-Jones DM, Levy D (2000) Association of hyperglycemia with reduced heart rate variability (The Framingham Heart Study). Am J Cardiol 86:309-312. doi:10.1016/S0002-9149(00)00920-6
Singh JP, Larson MG, O’Donnell CJ, Tsuji H, Corey D, Levy D (2002) Genome scan linkage results for heart rate variability (the Framingham Heart Study). Am J Cardiol 90:1290-1293. doi:10.1016/S0002-9149(02)02865-5

Sinnreich R, Kark JD, Friedlander Y, Sapoznikov D, Luria MH (1998) Five minute recordings of heart rate variability for population studies: repeatability and age-sex characteristics. Heart 80:156-162

Tsuji H, Larson MG, Venditti FJ Jr, Manders ES, Evans JC, Feldman CL, Levy D (1996) Impact of reduced heart rate variability on risk for cardiac events. The Framingham Heart Study. Circulation 94:2850-2855

Tuomainen P, Peuhkurinen K, Kettunen R, Rauramaa R (2005) Regular physical exercise, heart rate variability and turbulence in a 6-year randomized controlled trial in middle-aged men: the DNASCO study. Life Sci 77:2723-2734. doi:10.1016/j.lfs.2005. 05.023

Vanzetti G (1966) An azide-methemoglobin method for hemoglobin determination in blood. J Lab Clin Med 67:116-126

von Scheele I, von Scheele B, Hansson G, Winman A, Theorell T (2005) Psychosocial factors and respiratory and cardiovascular parameters during psychophysiological stress profiling in working men and women. Appl Psychophysiol Biofeedback 30:125136. doi:10.1007/s10484-005-4309-6 